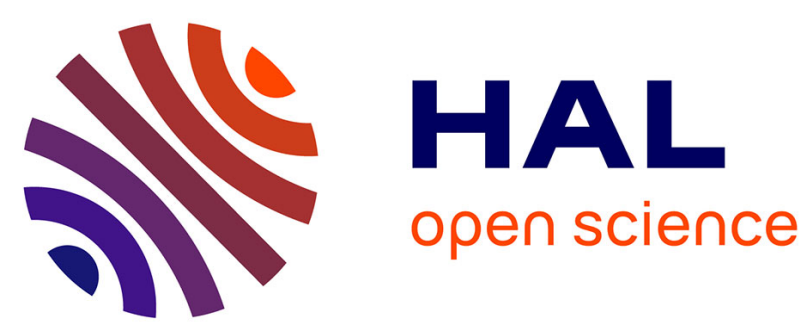

\title{
Investigation of Sc2O3 Based All-Solid-State EIS Structure for AlGaN/GaN HEMT pH sensor
}

Nossikpendou Yves Sama, Andrew Hathcock, Dongyuan He, Thi Quynh Phuong Vuong, Soufiane Karrakchou, Taha Ayari, Adama Mballo, Chris Bishop, Yacine Halfaya, Hafsa Bouhnane, et al.

\section{To cite this version:}

Nossikpendou Yves Sama, Andrew Hathcock, Dongyuan He, Thi Quynh Phuong Vuong, Soufiane Karrakchou, et al.. Investigation of Sc2O3 Based All-Solid-State EIS Structure for AlGaN/GaN HEMT pH sensor. 2019 IEEE SENSORS, Oct 2019, Montreal, Canada. pp.8956762, 10.1109/SENSORS43011.2019.8956762 . hal-02870737

\section{HAL Id: hal-02870737 https://hal.science/hal-02870737}

Submitted on 16 Jun 2020

HAL is a multi-disciplinary open access archive for the deposit and dissemination of scientific research documents, whether they are published or not. The documents may come from teaching and research institutions in France or abroad, or from public or private research centers.
L'archive ouverte pluridisciplinaire $\mathbf{H A L}$, est destinée au dépôt et à la diffusion de documents scientifiques de niveau recherche, publiés ou non, émanant des établissements d'enseignement et de recherche français ou étrangers, des laboratoires publics ou privés. 


\title{
Investigation of $\mathrm{Sc}_{2} \mathrm{O}_{3}$ Based All-Solid-State EIS Structure for $\mathrm{AlGaN} / \mathrm{GaN}$ HEMT $\mathrm{pH}$ sensor
}

\author{
Nossikpendou Yves Sama ${ }^{(1)}$, Andrew Hathcock ${ }^{(2)}$, Dongyuan $\mathrm{He}^{(2)}$, Thi Quynh Phuong Vuong ${ }^{(1)}$, Soufiane \\ Karrakchou $^{(1,2)}$, Taha Ayari ${ }^{(1,2)}$, Adama Mballo ${ }^{(1,2)}$, Chris Bishop ${ }^{(4)}$, Hafsa Bouhnane ${ }^{(4)}$, Simon Gautier ${ }^{(4)}$, Ali \\ Ahaitouf ${ }^{(1)}$, Jean Michel Matray ${ }^{(3)}$, Jean Paul Salvestrini ${ }^{(1,2)}$ and Abdallah Ougazzaden ${ }^{(1,2)}$ \\ (1) UMI 2958, Georgia Tech - CNRS, 57070, Metz, France \\ (2) Georgia Institute of Technology, School of Electrical and Computer Engineering, GT-Lorraine, 57070, Metz, France \\ (3) Institut de Radioprotection et de Sûreté Nucléaire (IRSN), BP17, Fontenay-aux-Roses, 92262, France
}

(4) Institut Lafayette, 2 rue Marconi, 57070, Metz, France

\begin{abstract}
In this work, an all-solid-state electrolyteinsulator-semiconductor (EIS) device is developed for $\mathrm{pH}$ sensing performance evaluation of insulating materials. The EIS capacitor incorporates scandium oxide $\left(\mathrm{Sc}_{2} \mathrm{O}_{3}\right)$ sensing film deposited on undoped gallium nitride (u-GaN) by thermal evaporation. The structural and morphological features of the thin films annealed at different temperature $\left(650-850^{\circ} \mathrm{C}\right)$, were investigated through $\mathrm{X}$-ray diffraction and AFM analysis. $A$ gold wire with diameter of $25 \mu \mathrm{m}$ was bonded on the device and served as the quasi reference electrode for the $\mathrm{C}-\mathrm{V}$ measurements and $\mathrm{pH}$ sensitivity characterizations. After correction of the measured capacitance regarding the $\mathrm{pH}$ dependent variation of the standard potential $\mathrm{E}^{0}(\mathrm{pH})$ of gold, the $\mathrm{Sc}_{2} \mathrm{O}_{3}$ EIS capacitor prepared with an annealing at $650^{\circ} \mathrm{C}$ exhibited a linear response with a sensitivity of $40 \mathrm{mV} / \mathrm{pH}$ while the device with the as-deposited $\mathrm{Sc}_{2} \mathrm{O}_{3}$ film showed nonlinear behavior and, those annealed at temperature higher than $650^{\circ} \mathrm{C}$ were shown to be insensitive to $\mathrm{pH}$ variation.
\end{abstract}

Keywords-MIS; EIS; quasi reference electrode; $p H$ sensor; $\mathrm{Sc}_{2} \mathrm{O}_{3} ;$ undoped GaN.

\section{INTRODUCTION}

The French project of long-term deep geological disposal of high and medium activity radioactive waste (Cigéo project) involves the use of large volume of cementitious materials embedded in a clay rock. In this context, IRSN, the French public expert in charge of the scientific evaluation of the nuclear and radiological risks, seeks to experimentally evaluate the $\mathrm{pH}$ of cementitious materials as a proxy for the aging of concrete structures in contact with clay materials. The diffusive exchange between the two environments could be problematic since it can affect the intrinsic properties of the materials in contact, leading to issues in the durability of the cement-based infrastructures [1]. To monitor and model this exchange, $\mathrm{pH}$ measurement of the water trapped in the pores of the concrete is a key point [2]. Conventional $\mathrm{pH}$ sensors (glass electrode [3]) cannot be used in such a harsh environment. Therefore, with the aim of long-term monitoring of storage facilities, we propose to use AlGaN/GaN-based HEMT (High Electron Mobility Transistor) sensors (see Fig. 1, with functionalized gate) which have been shown to be able to handle harsh conditions $[4,5]$. Such devices can be also grown on top of h-BN layer allowing their lift-off and report on other substrate to improve their performance [6].

This kind of sensor, called ion sensitive field effect transistors (ISFETs) is being increasingly used for detection of ionic activity in various application fields such as chemistry, medicine, biology, etc. An ISFET structure is a modified Metal-Oxide-Semiconductor Field-Effect Transistor (MOSFET) whose metal gate is replaced by an electrolyte solution to be tested and an external reference electrode which provides the electrical connection [7-10]. This device which was first demonstrated by Piet Bergveld in 1970 [7] has the advantage to combine both the sensing and the transducing functions into one small and rapid device with CMOS system integration compatibility in multiple ion sensors.

To fabricate these devices, silicon and its oxide have traditionally been used because of their outstanding performance, availability and ease of manufacturing. This kind of materials cannot unfortunately handle harsh environment. Heterostructures and quantum structures including III-V and II-VI compounds semiconductors have also demonstrated interest in various types of chemicalsensing devices for biochemical processes [11-14]. For the gate functionalization, several metal oxides such as $\mathrm{Si}_{3} \mathrm{~N}_{4}$, $\mathrm{Al}_{2} \mathrm{O}_{3}, \mathrm{ZrO}_{2}, \mathrm{HfO}_{2}, \mathrm{Ta}_{2} \mathrm{O}_{5} \ldots$ [15-18] have been extensively studied, but most of them degrade when exposed to strong alkaline medium. In contrary, scandium oxide $\left(\mathrm{Sc}_{2} \mathrm{O}_{3}\right)$, with a band gap of $6.3 \mathrm{eV}$ and dielectric constant of 14, unlike other metal oxides, is compatible with strongly alkaline medium like cementitious materials. Furthermore, ISFET with glass reference electrode has been already demonstrated $[13,15,18]$.

This work aims to investigate $\mathrm{pH}$ sensitivity of a $\mathrm{Sc}_{2} \mathrm{O}_{3} / \mathrm{u}-$ GaN based EIS and MIS devices (see Fig. 1), in order to optimize the growth and annealing parameters of the $\mathrm{Sc}_{2} \mathrm{O}_{3}$ layer, which will be then deposited on top of AlGaN/GaN HEMT transistor gate, to form AlGaN/GaN-based ISFET $[3,17]$ with on chip integrated quasi reference electrode (instead of conventional fragile glass electrode).

The paper presents the fabrication process of a simple and combined EIS/MIS capacitor using $\mathrm{Sc}_{2} \mathrm{O}_{3}$ and $\mathrm{u}-\mathrm{GaN}$, as well as the $\mathrm{C}-\mathrm{V}(\mathrm{pH})$ measurement set up and sensitivity 
extraction, using a non-conventional reference electrode, with the possibility to measure small volumes of electrolyte. The evolution of sensitivity to hydrogen ions (in the $\mathrm{pH}$ range of interest 7-13) as a function of postdeposition annealing temperature is discussed based on structural and morphological (X-ray diffraction and atomic force microscopy) analysis coupled with measured I-V curves.
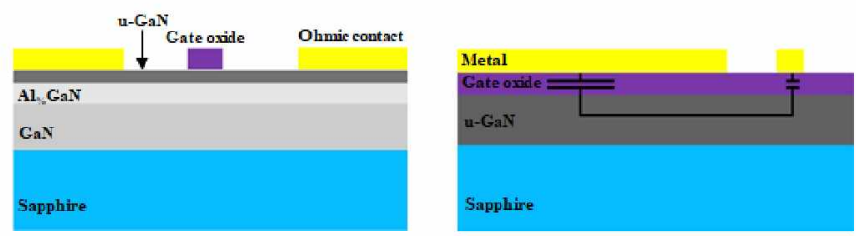

Fig. 1: HEMT (left) and MIS (right) structures.

\section{EXPERIMENTAL}

\section{A. Growth and device fabrication}

A $3.5 \mu \mathrm{m}$-thick undoped GaN was grown by MOCVD (Metal Organic Chemical Vapor Deposition) on a sapphire substrate. The details about u-GaN layer growth conditions can be found in [20]. Prior to $\mathrm{Sc}_{2} \mathrm{O}_{3}$ deposition, $\mathrm{u}-\mathrm{GaN}$ layer was solvent-cleaned and HF treated. Then thermal evaporation was carried out using $99.99 \%$ pure $\mathrm{Sc}_{2} \mathrm{O}_{3}$ pellets (Kurt J. Lesker). $20 \mathrm{~nm}$-thick $\mathrm{Sc}_{2} \mathrm{O}_{3}$ was deposited at substrate temperature of $200^{\circ} \mathrm{C}$. Then, a one hour-postdeposition annealing (PDA) at different temperatures $\left(650^{\circ} \mathrm{C}, 750^{\circ} \mathrm{C}\right.$ and $850^{\circ} \mathrm{C}$ ) in $\mathrm{N}_{2}$ atmosphere was realized, for comparison with the as-deposited film. The fabrication procedure of MIS and EIS structures includes the materials growth, metallization after photolithography, PDMS (polydimethylsiloxane) coating and localized openings using biopsy punch (for electrical contact and formation of a reservoir for EIS characterizations). A Au/Ti (100/10 nm) bilayer was deposited by e-beam evaporator for metallization. The last step of the fabrication is gold wire (with diameter of $25 \mu \mathrm{m}$ ) bonding between two $\mathrm{Au} / \mathrm{Ti}$ contacts located in two different reservoirs. Instead of the usual deposition of metal on the backside of the semiconductor substrate, a large capacitive virtual ground contact $(\mathrm{Au} / \mathrm{Ti})$ around the MIS gate contact and EIS reservoir [19] has been used. The ground contact was made large enough so that its capacitance is much higher than the one of the MIS and EIS capacitors to study. The operation principle of the EIS structure lies in the flatband voltage dependence on the surface potential at the insulator-electrolyte interface. This flat-band voltage for an ISFET or EIS device is [15]:

$\mathrm{V}_{\mathrm{FB}}=\mathrm{E}_{\mathrm{Tef}}-\psi_{0}+\chi_{\text {sol }}-\Phi_{\mathrm{S}} / q-\left(\mathrm{Q}_{\mathrm{ox}}+\mathrm{Q}_{\mathrm{ss}}\right) / \mathrm{C}_{\mathrm{ox}}$

where $\mathrm{E}_{\text {ref }}$ is the potential of the reference electrode, $\psi_{0}$ is the $\mathrm{pH}$-dependent surface potential, $\chi_{\text {sol }}$ is the surface dipole potential of the solution, $\Phi_{\mathrm{S}}$ is the work function of the electrons in the semiconductor, $q$ is the elementary charge, $\mathrm{Q}_{\mathrm{ox}}$ is the charge located in the oxide, $\mathrm{Q}_{\mathrm{SS}}$ is the charge located on the surface and interface, and $\mathrm{C}_{\mathrm{ox}}$ is the gate oxide capacitance.

\section{B. Structural and electrical characterizations}

The crystallinity of the different $\mathrm{Sc}_{2} \mathrm{O}_{3}$ films were analyzed using high-resolution X-ray diffraction (HRXRD) in Panalytical X'pert Pro MRD system with $\mathrm{Cu} \mathrm{K} \alpha$ radiation in triple axis mode. The surface morphology and roughness have been analyzed by AFM. Fig. 2 shows the electrical characterization setup for MIS and EIS capacitors. A Keysight E4990A impedance analyzer was used for C-V measurement. The applied small ac signal was $10 \mathrm{kHz} / 50 \mathrm{mV}$. Commercial $\mathrm{pH}$ buffer solutions (with $\mathrm{pH} 7,10,11,12$ and 13) were used to evaluate the sensitivity of the EIS sensor.

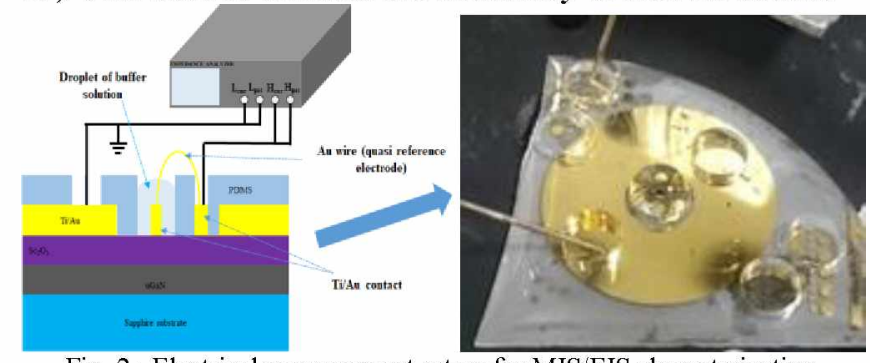

Fig. 2 : Electrical measurement set up for MIS/EIS characterization.

\section{RESULTS AND DISCUSSION}

The results of XRD analysis are presented on Fig. 3. From the $2 \theta-\omega$ scan recorded in the range $10^{\circ}$ to $70^{\circ}$, only the peak corresponding to the $\mathrm{Sc}_{2} \mathrm{O}_{3}$ (211) plane can be seen for all the films (annealed and as-deposited). The intensity of the peak increases and its FWHM decreases when the annealing temperature is increased. Also, the $2 \theta$ position of the peak is shifted towards higher values when the annealing temperature is increased. These results point out the effect of annealing on the crystallographic features (lattice parameter, crystallite size and microstrain) and indicates a better crystallinity for $\mathrm{Sc}_{2} \mathrm{O}_{3}$ films annealed at $750^{\circ} \mathrm{C}$ and $850^{\circ} \mathrm{C}$.

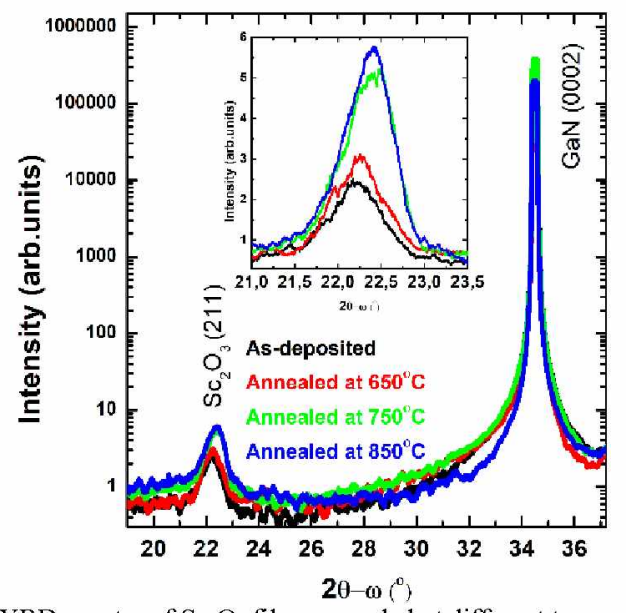

Fig. 3: XRD spectra of $\mathrm{Sc}_{2} \mathrm{O}_{3}$ films annealed at different temperatures.

Figure 4 shows the surface morphology of the $\mathrm{Sc}_{2} \mathrm{O}_{3}$ films obtained by AFM analysis. The films annealed at $750^{\circ} \mathrm{C}$ and $850^{\circ} \mathrm{C}$ are clearly granular with similar roughness of $1.4 \mathrm{~nm}$ and $1.3 \mathrm{~nm}$ respectively. The as-deposited film does not show a typical surface morphology (relatively smooth but not flat) 
and has a roughness of $0.6 \mathrm{~nm}$. The film annealed at $650^{\circ} \mathrm{C}$ has a very flat surface with roughness as low as $0.2 \mathrm{~nm}$.
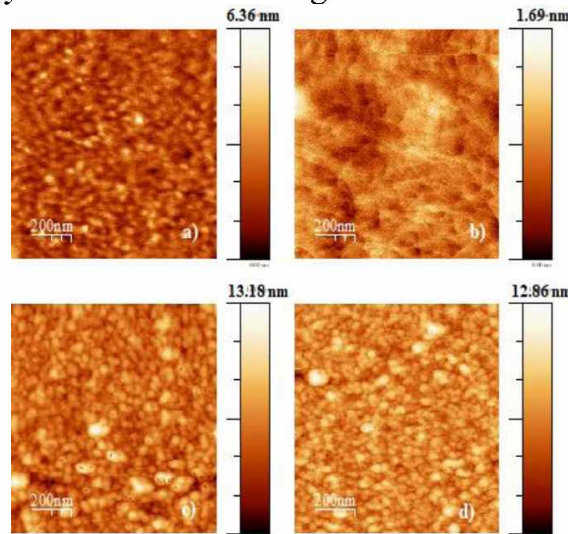

Fig. 4: Surface morphology obtained by $\mathrm{AFM}$ of $\mathrm{Sc}_{2} \mathrm{O}_{3}$ films annealed at different temperatures: a) as-deposited, b) $650^{\circ} \mathrm{C}$, c) $750^{\circ} \mathrm{C}$, d) $850^{\circ} \mathrm{C}$.

Fig. 5 shows the measured $\mathrm{C}-\mathrm{V}$ curves for the $\mathrm{Sc}_{2} \mathrm{O}_{3}$ films annealed at $650^{\circ} \mathrm{C}$ and $850^{\circ} \mathrm{C}$, and their dependence with $\mathrm{pH}$. Films annealed at $850^{\circ} \mathrm{C}$ (and $750^{\circ} \mathrm{C}$ not shown here) are non-sensitive to $\mathrm{pH}$. The as-deposited film (not shown here) has been shown to exhibit some sensitivity but with a nonlinear behavior. Only the $650^{\circ} \mathrm{C}$-annealed film has been shown to have a linear sensitivity to $\mathrm{pH}$.
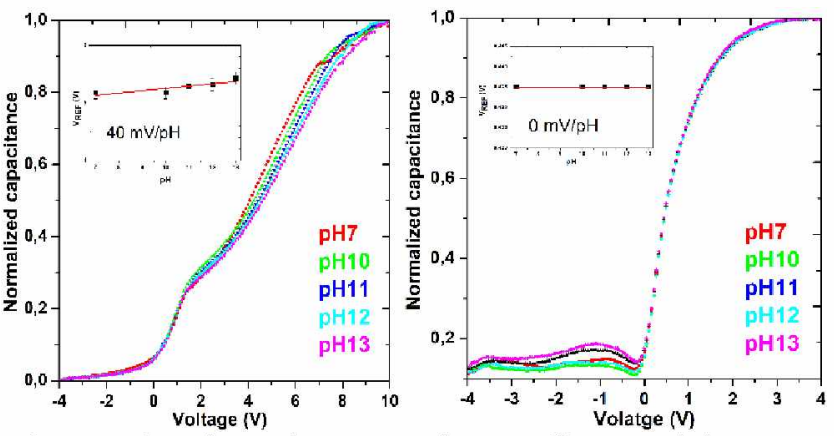

Fig. 5: pH dependence of C-V curves for $\mathrm{Sc}_{2} \mathrm{O}_{3}$ films annealed at $650^{\circ} \mathrm{C}$ (left) and $850^{\circ} \mathrm{C}($ right $)$.

Unlike the conventional reference electrode such as $\mathrm{Ag} / \mathrm{AgCl}$ electrode which has a constant potential regardless the variation of $\mathrm{pH}$, the potential of the quasi reference electrode varies as a function of $\mathrm{pH}$. Considering the $\mathrm{pH}$-dependence of the standard potential of $\mathrm{Au}$ micro wire (the quasi reference electrode), the sensitivity value was corrected by weighting the measured potentials at 0.5 of the normalized C$\mathrm{V}$ curves, with the respective values of the standard potential $\mathrm{E}^{\mathrm{O}}(\mathrm{pH})$ of $\mathrm{Au}$ for a given $\mathrm{pH}$. These standard potentials were obtained by linear interpolation from the theoretical data at $\mathrm{pH}=0$ and $\mathrm{pH}=14$ reported in the literature $[22,23]$. The correction is made based on the principle of the potential which is effectively applied to the EIS capacitor, according to the distribution of voltage across the measurement circuit. After correction, a sensitivity of $40 \mathrm{mV} / \mathrm{pH}$ is obtained for the EIS capacitor with the $650^{\circ} \mathrm{C}$-annealed $\mathrm{Sc}_{2} \mathrm{O}_{3}$ film. Fig. 6 shows the measured I-V curves of the MIS capacitors. For all the MIS capacitors, the current density is lower in the positive voltage range. This can be attributed to the formation of a depletion region when the positive voltage is added [24].

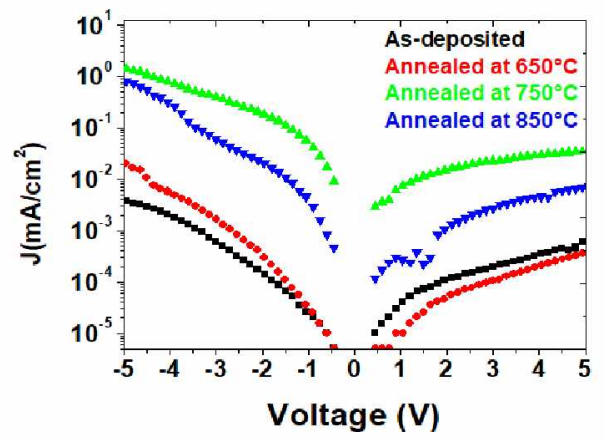

Fig. 6: I-V curves measured on the MIS capacitors.

The current density increases with the increase of the annealing temperature except for the film annealed at $650^{\circ} \mathrm{C}$. This result is consistent with the fact that the grain boundaries (as shown in Fig. 4) which are leakage channels [24], increase with the annealing temperature except for the sample annealed at $650^{\circ} \mathrm{C}$ which does not show a grain structure. In the light of the whole results, it seems that the $\mathrm{pH}$ sensitivity is closely related to the level of insulation and/or surface morphology of the dielectric material.

These set of data show that the best sensitivity is obtained for the dielectric material with the lowest leakage current corresponding to the flattest morphology. However, this is not enough to explain the peculiarity of the $\mathrm{pH}$-insensitivity of some of the EIS sensors. Further investigation is needed to understand this. The pH-sensitivity in EIS structures being governed by the mechanisms of surface ion adsorption and charge modulation at the oxide-semiconductor interface, surface and interface chemical composition as well as interface states analysis of the capacitors would be relevant. The understanding of this insensitivity using metal oxides could be an advantage for the development of high quality and stable REFETs. Furthermore, by optimizing the annealing temperature, time and atmosphere, the Nernstian $(59.2 \mathrm{mV} / \mathrm{pH})$ or even super-Nernstian $\mathrm{pH}$ sensitivity may be reached with our thermal evaporated $\mathrm{Sc}_{2} \mathrm{O}_{3}$ on $\mathrm{u}-\mathrm{GaN}$.

\section{CONCLUSION}

A study of $\mathrm{Sc}_{2} \mathrm{O}_{3}$-based all-solid-state EIS structure was presented. $\mathrm{Sc}_{2} \mathrm{O}_{3}$ films annealed at $650^{\circ} \mathrm{C}$ in $\mathrm{N}_{2}$ for one hour were shown to exhibit a linear sensitivity of $40 \mathrm{mV} / \mathrm{pH}$. This performance may be optimized by adjusting further the annealing parameters. Also, non-conventional MIS/EIS structure is shown to be suitable for rapid investigation of sensitive insulating materials.

The next step will be the integration of the optimized $\mathrm{Sc}_{2} \mathrm{O}_{3}$ layer on top of $\mathrm{AlGaN} / \mathrm{GaN}$ HEMT transistor gate, to form $\mathrm{AlGaN} / \mathrm{GaN}$-based ISFET with on chip integrated quasi reference electrode.

\section{ACKNOWLEDGMENT}

This study has been funded by the Institut de Radioprotection et de Sûreté Nucléaire (IRSN) and the French PIA project "Lorraine Université d'Excellence" (ANR-15-IDEX-04LUE). 


\section{REFERENCES}

[1] A. Atkinson, A. K. Nickerson, "The diffusion of ions through watersaturated cement," Journal of Materials Science 19, 3068-3078 (1984).

[2] Ali Behnood, Kim Van Tittelboom, Nele De Belie, "Methods for measuring $\mathrm{pH}$ in concrete: A review," Construction and Building Materials 105, 176-188 (2016).

[3] Jieying Xing, Dejia Huang, Yaqiong Dai, Yuebo Liu, Yuan Ren, Xiaobiao Han, Hang Yang, Yaqian Hou, Zhisheng Wu, Yang Liu, and Baijun Zhang, "Influence of an integrated quasi-reference electrode on the stability of all-solid-state $\mathrm{AlGaN} / \mathrm{GaN}$ based $\mathrm{pH}$ sensors," Journal of Applied Physics 124, 034904 (2018).

[4] Chris Bishop, Yacine Halfaya, Ali Soltani, Suresh Sundaram, Xin Li, Jérémy Streque, Youssef El Gmili, Paul L. Voss, Jean Paul Salvestrini and Abdallah Ougazzaden, "Experimental study and device design of $\mathrm{NO}, \mathrm{NO} 2$ and $\mathrm{NH} 3$ gas detection for a wide dynamic and large temperature range using $\mathrm{Pt} / \mathrm{AlGaN} / \mathrm{GaN}$ HEMT," IEEE SENSORS, VOL. 16, NO. 18 (2016).

[5] Yacine Halfaya, Chris Bishop, Ali Soltani, Paul L. Voss, Suresh Sundaram, Vincent Aubry, Jean-Paul Salvestrini and Abdallah Ougazzaden, "Investigation of the performance of HEMT-based NO, $\mathrm{NO}_{2}$ and $\mathrm{NH}_{3}$ exhaust gas sensors for automotive antipollution systems," Sensors 16(3) (2016) 273.

[6] T Ayari, C Bishop, MB Jordan, S Sundaram, X Li, S Alam, Y ElGmili, Gilles Patriarche, Paul L Voss, Jean Paul Salvestrini, Abdallah Ougazzaden, "Gas sensors boosted by two-dimensional h-BN enabled transfer on thin substrate foils: towards wearable and portable applications", Scientific reports 7 (1), (2017) 15212

[7] P. Bergveld, "Development of an ion-sensitive solid-state device for neurophysiological measurements," IEEE Trans Biomed Eng. 17, 70$71(1970)$

[8] P. Bergveld, "Thirthy years of ISFETOLOGY: what happened in the past 30 years and what may happen in the next 30 years," Sensors and Actuators B 88, 1-20 (2003).

[9] Kokab B. Parizi, Xiaoqing Xu, Ashish Pal, Xiaolin Hu and H.S. Philip Wong, "ISFET pH sensitivity: counter-ions play a key role," Sci. Rep. 7, 41305; doi: 10.1038/srep41305 (2017)

[10] N. Moser, T. S. Lande, C. Toumazou and P. Georgiou, "ISFETs in CMOS and emergent trends in instrumentation: a review," IEEE Sensors Journal, vol. 16, no. 17, pp. 6496-6514, Sep. 2016.

[11] Takuya Kokawa, Taketomo Sato, Hideki Hasegawa and Tamotsu Hashizume, "Liquid-phase sensors using open-gate AlGaN high electron mobility transistor structure," J. Vac. Sci. Technol. B 24(4), 2006.

[12] Yan Dong, Dong-Hyeok Son, Quan Dai, Jun-Hyeok Lee, Chul-Ho Won, Jeong-Gil Kim, Dunjun Chen, Jung-Hee Lee, Hai Lu, Rong Zhang and Youdou Zheng, "High sensitive $\mathrm{pH}$ sensor based on AllnN/GaN heterostructure transistor," Sensors 2018, 18, 1314 (2018).

[13] Pankaj Kumar, Siddheswar Maikap, Amit Prakash and Ta-Chang Tien, "Time-dependent $\mathrm{pH}$ sensing phenomena using $\mathrm{CdSe} / \mathrm{ZnS}$ quantum dots in EIS structure," Nanoscale Research Letters 9: 179 (2014).

[14] Yuan Tan, Yanying Wang. Mingshi Li, Xiaoxue Ye, Tsunghsueh Wu, Chunya $\mathrm{Li}$, "Enhanced photoelectrochemical immunosensing of cardiac troponin I based on energy transfer between N-Acetyl-LCysteine capped $\mathrm{CdAgTe}$ quantum dots and dodecahedral $\mathrm{Au}$ nanoparticles", Biosens. Bioelectron., 91, 741 (2017).

[15] Tung-Ming Pan, Chih-Wei Wang and Ching-Yi Chen, "Structural properties and sensing performance of $\mathrm{CeY}_{\mathrm{x}} \mathrm{O}_{\mathrm{y}}$ sensing films for electrolyte-insulator-semiconductor pH sensors," Sci. Rep. 7, 2945; doi: 10.1038/s41598-017-03209-7 (2017).

[16] Xinge Yu, Tobin J. Marks and Antonio Facchetti, "Metal oxides for optoelectronic applications" Naure Materials, vol 15, 383-396; doi: 10.1038/NMAT4599 (2016).

[17] Shahriar Jamasb, "Continuous monitoring of $\mathrm{pH}$ and blood gases using ion-sensitive and gas-sensitive field effect transistors operationg in the amperometric mode in presence of drift," IEEE TRANSACTIONS ON ELECTRON DEVICES, VOL. 65, NO. 1 (2018)

[18] V. Jankovic and J. P. Chang, " $\mathrm{HfO}_{2}$ and $\mathrm{ZrO}_{2}$-based microchemical ion sensitive field effect transistor (ISFET) sensors: simulation and experiment," Journal of the Electrochemical Society, 158 (10) P115P117 (2011).

[19] Ju-Young Pyo, Jin-Hyeok Jeon, Yumin Koh, Chu-young Cho, HyeongHo Park, Kyung-Ho Park, Sang Woon Lee and Won-Ju Cho, "AlGaN/GaN high-electron-mobility transistor $\mathrm{pH}$ sensor with extended gate platform," AIP Advances 8,085106 (2018).

[20] S. Gautier, C. Sartel, S. Ould-Saad, J. Martin, A. Sirenko and A. Ougazzaden, "GaN materials growth by MOVPE in a new-design reactor using DMHy and $\mathrm{NH}_{3}$," J. Cryst. Growth, vol 298, 428-432 (2007).

[21] Ki-Sik Im, Jeong-Gil Kim, Sindhuri Vodapally, Raphaël Caulminole, Sorin Cristoloveanu, Jung-Hee Lee, "Capacitance-voltage characterization of $\mathrm{Al}_{2} \mathrm{O}_{3} / \mathrm{GaN}$-on-insulator (GaNOI) structures with TMAH surface treatment," Microelectronic Engineering 178, 217-220 (2017).

[22] Peter Kurzweil, "Metal oxides and ion-exchaning surfaces as $\mathrm{pH}$ sensors in liquids: state-of-the-art and outlook," Sensors 2009, 9, 4955-4985.

[23] N. P. Finkelstein and R. D. Hancock, "A new approach to chemistry of gold," Gold bulletin (1974); DOI:10:1007/BF03215041

[24] Meijuan Zheng, Guozhen Zhang, Xiao Wang, Jiaxian Wan, Hao Wu and Chang Liu, "Effects of post-deposition annealing on $\mathrm{ZrO}_{2} / \mathrm{n}-\mathrm{GaN}$ MOS capacitors with $\mathrm{H}_{2} \mathrm{O}$ and $\mathrm{O}_{3}$ as the oxidizers" Nanoscale Research Letters 12: 267 (2017). 